This PDF is a simplified version of the original article published in Internet Archaeology. Enlarged images which support this publication can be found in the original version online. All links also go to the online version.

Please cite this as: Roskams, S. 2020 The Post-excavation Analysis and Archiving of Outputs from Complex, Multi-period Landscape Investigations: the example of Heslington East, York, Internet Archaeology 55. https://doi.org/10.11141/ia.55.7

\title{
The Post-excavation Analysis and Archiving of Outputs from Complex, Multi-period Landscape Investigations: the example of Heslington East, York
}

Steve Roskams

\section{Summary}

This article discusses the post-excavation analysis and archiving of data generated by fieldwork undertaken at Heslington East near York in the UK. This project, stretching over two decades, involved two commercial companies and a student training and local community element, and recently concluded with a thematic publication (Roskams and Neal 2020). The article has twin objectives. First, on a theoretical level, it reflects on the complex challenges that arise when attempting to combine diverse stratigraphic, spatial and assemblage data from different sources to reach meaningful interpretations of an extensive, multi-period landscape. Second, on a practical level, it aims to act as an introduction to the project's archives to make them accessible to future audiences, something that is essential if we are to enable any re-interpretation of the site. 


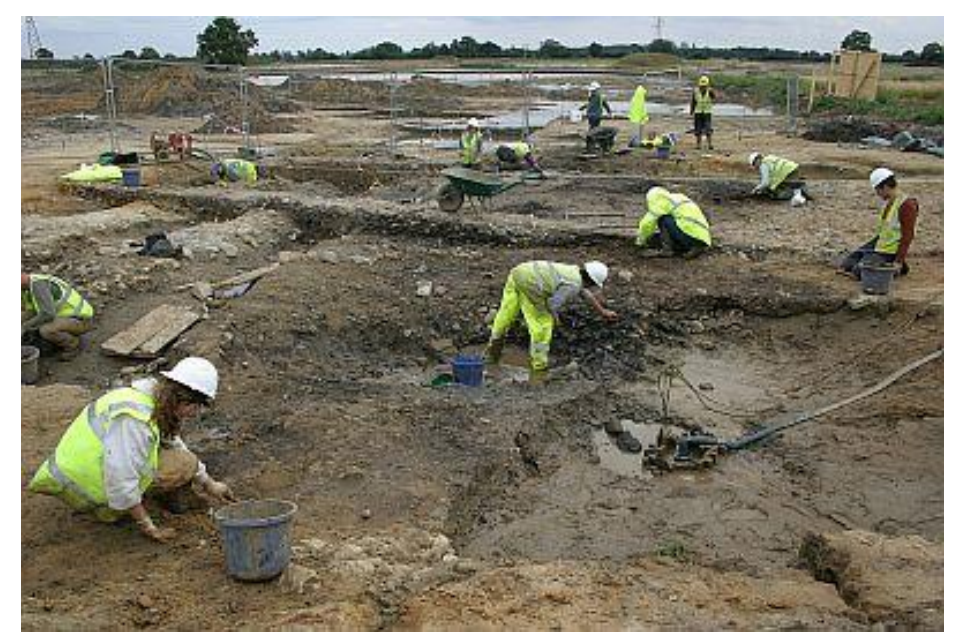

Prehistoric and Roman waterhole in the course of excavation (foreground) with associated complex of intercutting. linear landscape divisions beside it (left). (OYAT (Heslington East Excavation Archive)

I suggest that such archives embody a series of transformations. These comprise first the interpretation of reconnaissance and evaluation procedures, converted to generate an excavation strategy, something briefly summarised here. I then discuss at greater length: the processes of post-excavation analysis of stratigraphic and spatial data, and their relationship with the MoRPHE requirement (Historic England 2006) to select particular assemblages for detailed analysis; linking the latter, specialist reports on selected assemblages to preliminary interpretations of site evidence, an iterative process that creates more soundly based understanding; and the recasting of summaries of the most significant evidence in these secondary interpretations to fit the thematic organisation of the published report. I argue that each of these hierarchically ordered transformations needs to be understood if we are to facilitate effective re-use of site archives.

\section{Introduction}

This article reflects on the nature of post-excavation analysis in post-PPG16 and postMoRPHE eras (PPG16 1990; Historic England 2006), using work undertaken on a longterm fieldwork project at Heslington East (henceforth Heslington, for convenience). It has two objectives. The prioritisation of mitigation over destructive investigation in the last 30 years, as embodied in PPG16, means that much of our evidence from commercial contexts derives from myriad small-scale excavations written up only in grey literature reports (Evans 2013). So the first aim is to explore the complex challenges that arise when attempting to derive meaningful interpretations from numerous, dispersed interventions, and to draw out the implications of this situation for the content, and structure, of the resulting archives. Second, this piece acts as an introduction to Heslington's archives, in the hope of facilitating further analysis of the site.

Conventional fieldwork procedures in the UK currently comprise a sequence of subprojects: desk-based assessment and ground-based evaluation, ideally expressed as an outline deposit model; setting such a model beside evolving research agendas to define an excavation strategy for data gathering; and undertaking stratigraphic analysis and the 
assessment of assemblages, as per MoRPHE, to decide priorities for further specialist analyses. Only when the latter are completed can a formal publication programme be defined.

The Heslington project followed this overall sequence, but took place over two decades. Desk-top study of the development covering 120 hectares led to reconnaissance and evaluation in the early 2000s undertaken by the York Archaeological Trust (henceforth YAT). This involved fieldwalking across the whole development area (investigating 34\% of the total), geophysical prospection in specific zones (13\%) and trial trenching (2\%). There followed two phases of excavation. That in the west, carried out by YAT and covering $8 \%$ of the site, was completed in 2010 and followed by stratigraphic and various specialist analyses. That further east $(2 \%)$, carried out by a combination of the Department of Archaeology (DoA) and OnSite Archaeology (OSA), ended in 2013, succeeded by further post-excavation work. From 2017, these two parts of the project were drawn together to allow publication this year (Roskams and Neal 2020).

Work on the site not only extended over many years but, as noted previously, involved decision-making by different groups. Thus stratigraphic analysis after each phase of excavation varied between the organisations involved and work on assemblages was carried out at quite different times by different specialists with diverse approaches and priorities. Further, because the definition of assemblage priorities rested on contrasting stratigraphic foundations, later discussions of divergences between specialist outputs and initial stratigraphic interpretations, always an iterative conversation, were made still more complex. Finally, the authors of the synthesis selected from this considerable archive only what they felt were the most significant results. Hence that monograph does not claim to be the 'final word' on the site, merely a discussion of two people's view of different forms of human engagement with the Heslington landscape (the various specialist articles, 'popular' interim statements and so forth that appeared before that monograph were equally selective in their content).

The viewpoint of the authors, as expressed in the publication, is articulated in a series of themes. Their order is based on the belief that one must first understand the fundamental ways in which people exploited their immediate environment and its natural resources in terms of boundaries, food and other production (chs 2-5), before one can explore meaningfully matters such as domestic organisation, trade and exchange or ritual activity (chs 6-8). Obviously, such principles are not universally agreed. Finally, although this landscape is described thematically, Heslington did change over time. Yet pivotal points in its sequence of development do not fit easily into conventional period divisions. So the closing, chronological chapter (ch. 9) is organised instead around periods of significant transition.

The cross-cutting themes embodied in the monograph mean that any reader wishing to assess the accuracy and validity of its proposed interpretations has the challenging task of accessing a wide range of archival materials. Further, the structure of the latter documentation reflects a series of hierarchical transformations: from reconnaissance and evaluation to site recording; from site record to reporting the results of stratigraphic analysis and of detailed investigation of selected assemblages; from such reports to an integrated, descriptive account; and from this narrative to selected understandings in a published synthesis.

What follows describes in outline first the Heslington Project, then the Organisational Background in which it subsisted, followed by the processes of Reconnaissance, 
Evaluation and Excavation at Heslington. It then considers in more detail The General Character of Post-Excavation Analysis and Excavation Archives in order to contextualise Post-Excavation Assessment and Analysis at Heslington. The latter sections form the core of this article, allowing Conclusions to emerge concerning the transformations that occur in post-excavation analysis. Each needs to be understood to make the site archive usable, and this article tries to facilitate such endeavours.

\section{The Heslington Project}

The site is situated on a green belt zone on the fringes of York, a major historic town since its Roman foundation (Figure 1). The University of York's proposed expansion here created the need for an archaeological evaluation of this landscape to define a strategic response to this development threat. Thereafter, a combination of work by two commercial organisations, and by students undertaking fieldwork training and local communities, eventually resulted in the largest archaeologically investigated exposure of prehistoric and Roman activity in York's immediate hinterland.

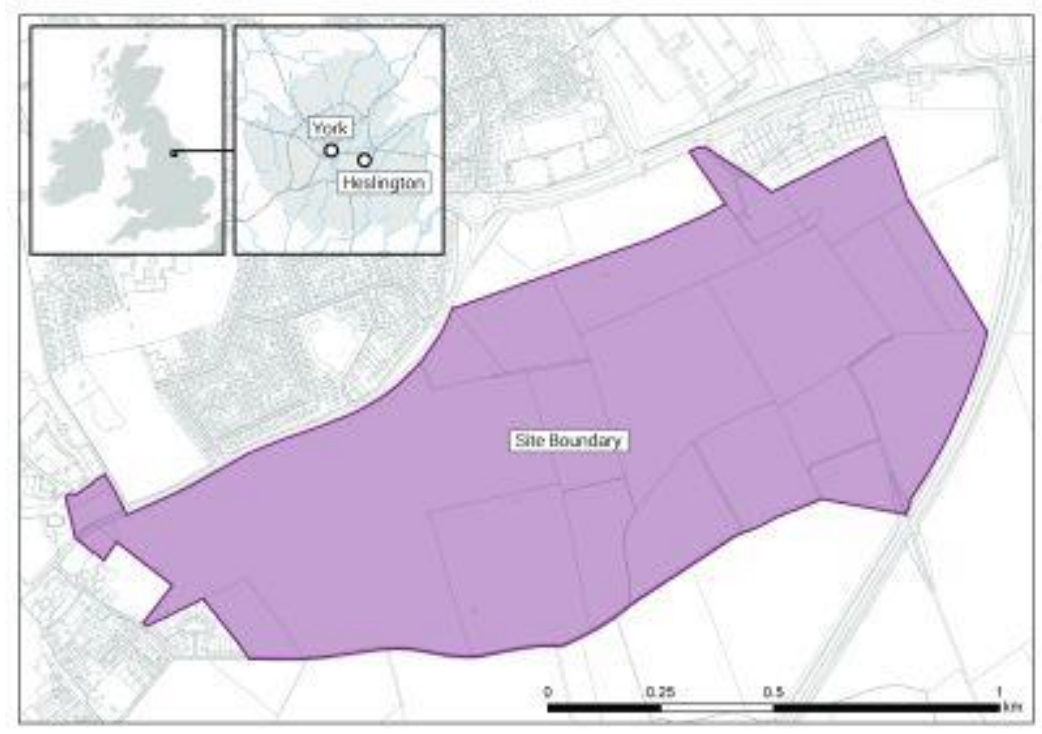

Figure 1: Site location plan (contains OS MasterMap® Topography Layer [FileGeoDatabase geospatial data], Scale 1:1250, Tiles: GB, Updated: 1 November 2017, Ordnance Survey (GB), Using: EDINA Digimap Ordnance Survey Service, http://digimap.edina.ac.uk, Downloaded: 2018-05-29 11:49:34.438)

Heslington lies at the centre of the low-lying Vale of York, a zone that has both shaped, and been shaped by, communities living there since the end of the last Ice Age. A glacial moraine bounds the site in the north and mobile groups passing along this hardstanding across The Vale utilised the adjacent landscape resources from at least the Neolithic period, notably to access water (Figure 2). This interaction took place with increasing regularity into the Bronze Age and, from c. $800 \mathrm{BCE}$, itinerant engagement gave way to more sedentary occupation involving the creation of landscape divisions. By C. 100 BCE, field systems and houses had been set out here. Such landholdings were transformed by monumental reorganisation from $c$. 200CE, followed by traces of more short-lived activity after, perhaps, 400CE. Various forms of medieval and modern agricultural land use, then new university building, mark the end of this sequence of occupation. 


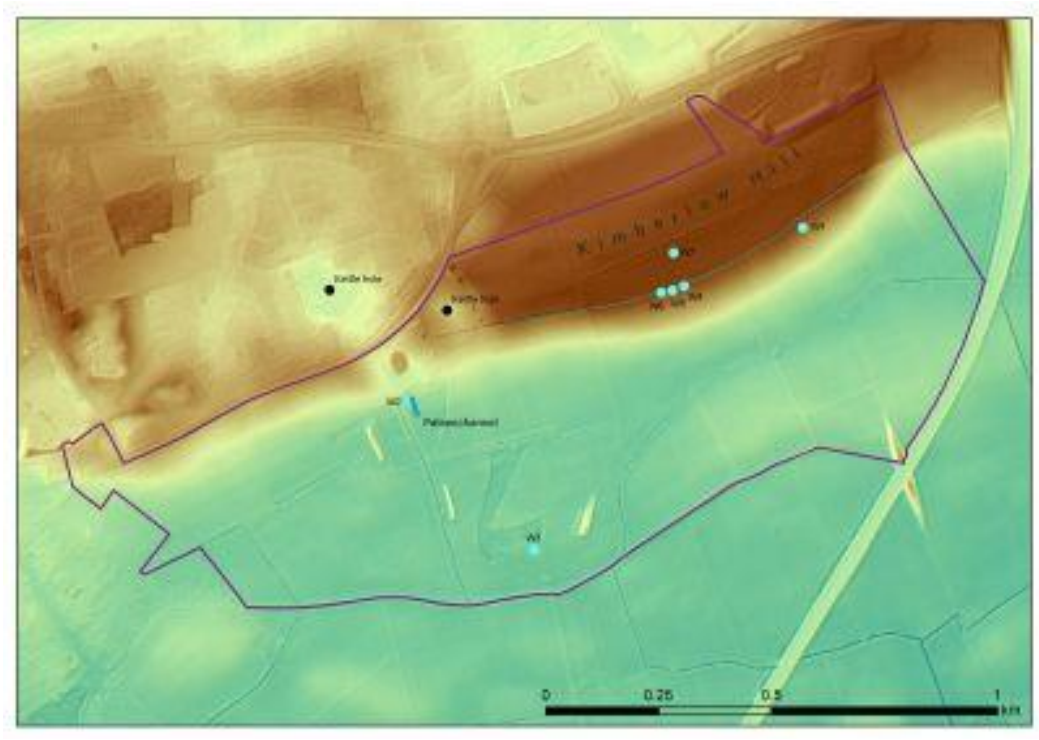

Figure 2: Site features on the edge of glacial moraine (brown) and water access points, kettle holes, palaeochannel, and wells

Of the various archives created by the project, the physical artefacts and hardcopy site records are the most straightforward to describe. The project generated c. 250 boxes of finds, the vast majority of which comprised animal bone, pottery and ceramic building materials, plus information on 5284 contexts with associated, hand-drawn spatial information. Nearly all physical assemblages and records will be stored at the designated local institution, the Yorkshire Museum (accession code YORYM: 2011.1129) and should thus be available in perpetuity.

The exceptions comprise only a sample of the Roman and medieval building material recovered, selected in line with the Museum's guidelines for reducing storage space; some animal bone, kept by the Department of Archaeology as a teaching collection; the human bone, most of which was reburied on the site in line with legal requirements (with a small portion retained, with permission, for experimental use within the Department); and those site records generated by YAT, stored in their online Integrated Archaeological Database (https://www.iadb.co.uk/iadb2017.php).

All digital documentation will be held by the Archaeology Data Service, including reports from initial reconnaissance and evaluation; spatial data, consolidated between projects into a single GIS; stratigraphic and assemblage reports from post-excavation analysis of all types; and descriptive syntheses of the various parts of the project. The complex structure of the latter documentation is the main focus of what follows.

\section{Organisational Background}

The work undertaken at Heslington is, in many ways, a direct expression of how archaeological fieldwork is carried out in the UK in the 21st century. The long economic boom post-World War II and the resulting 'rescue movement' (Rahtz 1974) created a fieldwork profession tasked with producing an 'archival record' in place of the site itself. In line with similar trends across Europe, archaeological endeavours thus became part of structure plans and environmental impact legislation. These changes generated new approaches to site recording, and to systematised assemblage analysis and sampling 
strategies (Roskams 2001, 23ff), yet also questioned the once seamless process of recording, interpreting and publishing archaeological fieldwork. Hence the notion of an archaeological archive set between, but linking, excavation and synthetic interpretation, became deeply embedded in archaeological practice.

If the 1970s portrayed archaeological fieldwork as rescuing threatened sites with informational potential, the 1990s saw it as an encounter with a fragile and irreplaceable resource requiring, where possible, in situ preservation. Hence a sequence of general reconnaissance and detailed evaluation, ideally brought together in a site-specific deposit model structured by spacing, status and preservation (Carver 2003, 61), was needed to define mitigation strategies. Alleviating impacts became fieldwork's first priority, full excavation its last (Orange and Perring 2017). This UK change again had its counterpart in mainland Europe (Cooney 2009; Novakoviç et al. 2016;

Stefánsdóttir 2019). Such an approach, decentring excavation by making it one element in a multi-stage sequence of activity, may alter public perception of what constitutes archaeological practice in the long term, with advantages for the discipline as a whole (Cherry 2011).

In addition to this change in principle, neoliberal policies meant that it was not the state but the developer, as 'polluter', that was now to pay for the fieldwork process. Developer funding has vastly increased the volume of archaeological data in the last 30 years (Darvill et al. 2019) and the profession has come to define itself in business terms (Landward Research Ltd 2014). Such sources of finance may not, in themselves, require the introduction of a deregulated model with competitive tendering (Demoule 2002; Depaepe 2016; Webley et al. 2012). Yet, where such a model has been adopted fully, as is the case in the UK, it is price, rather than the quality of any research design, that dictates the allocation of resources.

Hence economic cycles impact profoundly on today's fieldwork (Schlanger and Aitchison 2010), particularly when moving from boom to bust (e.g. in Ireland:

Ronayne 2008). Furthermore, commercialisation has placed many excavators on shortterm contracts, with specialist work undertaken by separate businesses operating at arm's length. This new, more mobile, profession is thus further divorced from local communities, paradoxically just when the latter most need 'their' archaeology, for example due to the same neoliberal forces homogenising town centres (Neal and Roskams 2013).

\section{Reconnaissance, Evaluation and Excavation at Heslington}

At Heslington, all of the above factors were eminently visible, affecting how fieldwork happened, how its data were analysed, how the resulting archives were constructed, and how interpretations are published and might reach (or fail to reach) their audience(s). Thus an initial desk-top study by an external consultant led to two different phases of commercial work carried out by competing businesses (YAT and OSA), the latter overseen by yet another consultant. An intervening, non-commercial element by the DoA facilitated student training and community engagement (the last an attempt to seal the growing rift between local people and their heritage noted above (Figure 3; see also Jackson et al. 2014). Furthermore, the majority of specialists employed to analyse 
the assemblages generated by the fieldwork operated on separate time scales. Most comprised self-employed individuals or small businesses, few of whom were based in York.

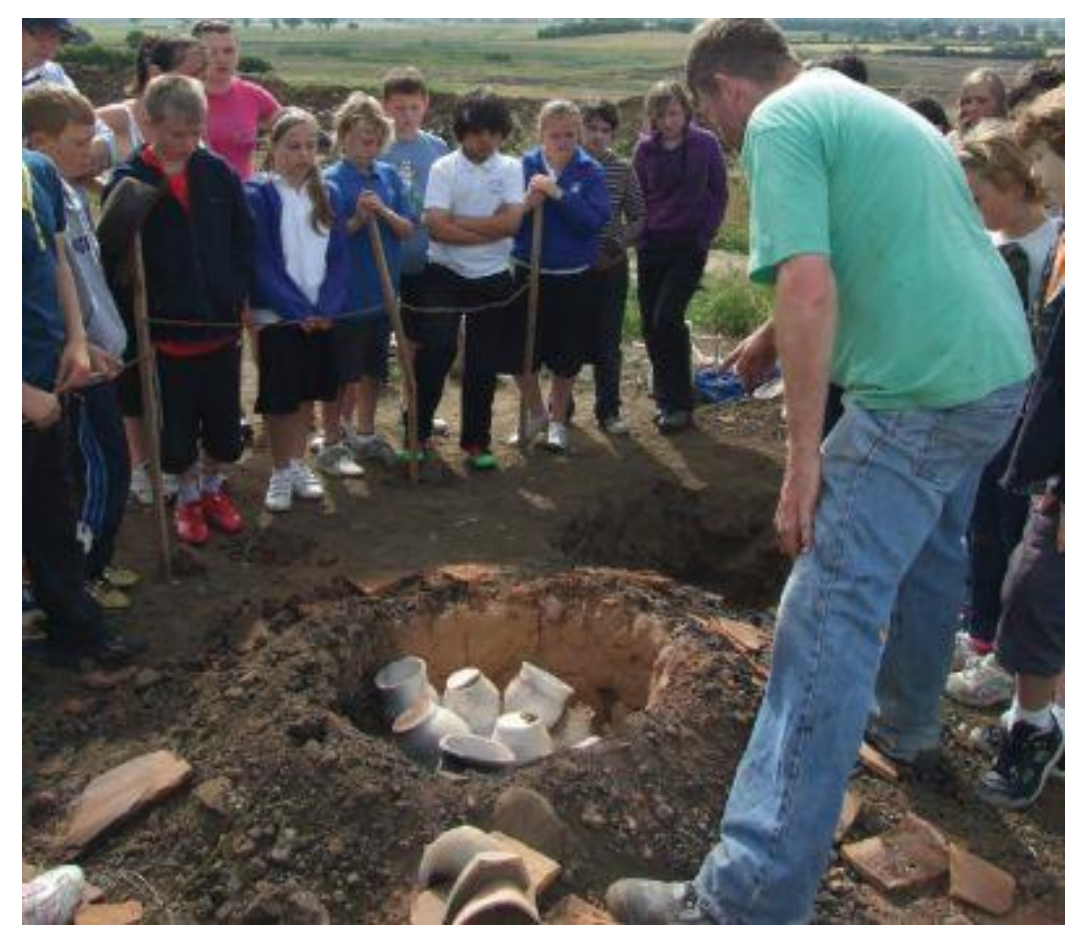

Figure 3: Schoolchildren learning to reconstruct a Roman kiln, part of an attempt to give local people a sense of heritage engagement and thus ownership

For the Heslington project, initial reconnaissance comprised a series of industrystandard desk-based assessments (Perring 1999) that emphasised the significance of prehistoric evidence, given the limited opportunities to investigate such periods near York's historic core. The more numerous Roman finds from the area included evidence for roads and prestigious burials, while Anglo-Saxon burials were found nearby in the mid-19th century. Medieval ploughing and various significant later buildings were also noted. This study argued for further desk-based, aerial photographic and geophysical work, followed by trial trenches and selective test-pitting, all undertaken by YAT. The information generated then allowed the definition of priority zones A1-3 and other subsidiary zones B1-7 (Figure 4) and period-based research objectives to be set out. Areas $A 1$ and $A 2$ were excavated on a commercial basis by YAT, with $A 3$, not under immediate threat of development, dedicated to student training and local community participation (DoA). 


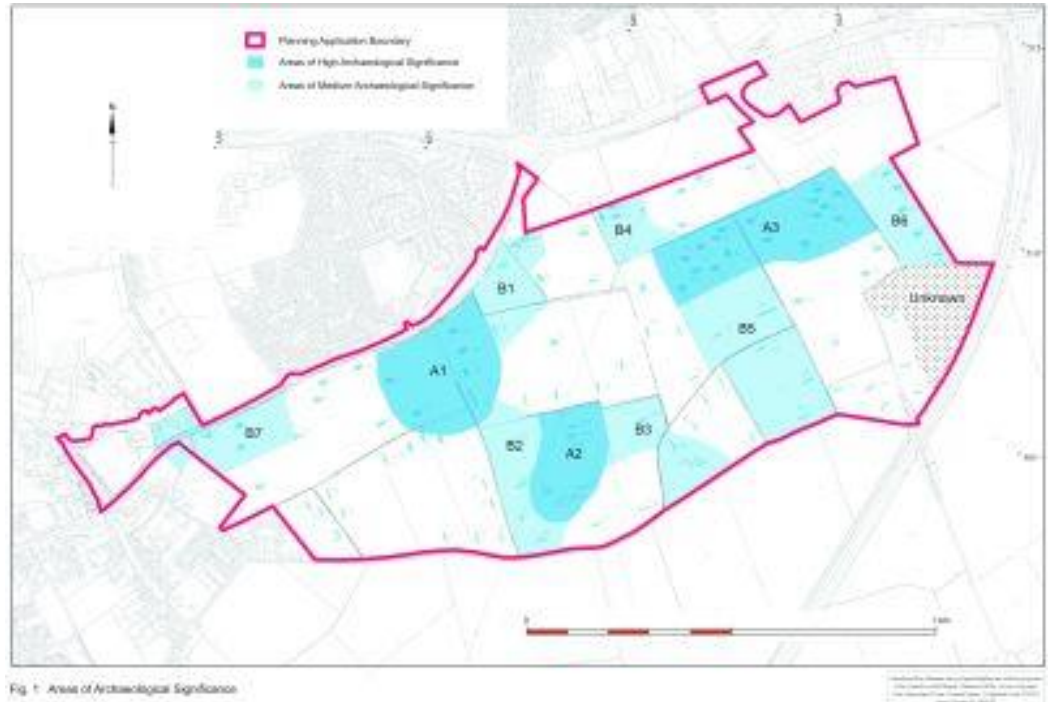

Figure 4: Definition of priority zones A1-A3 and subsidiary zones B1-B7 CYork Archaeological Trust

This extended timetable for the DoA sub-project allowed it to carry out: further fieldwalking, which now generated more meaningful patterning; additional geophysics, also identifying specific features; and extra trial trenches, set out in relation to detailed geophysical understanding (Figure 5).

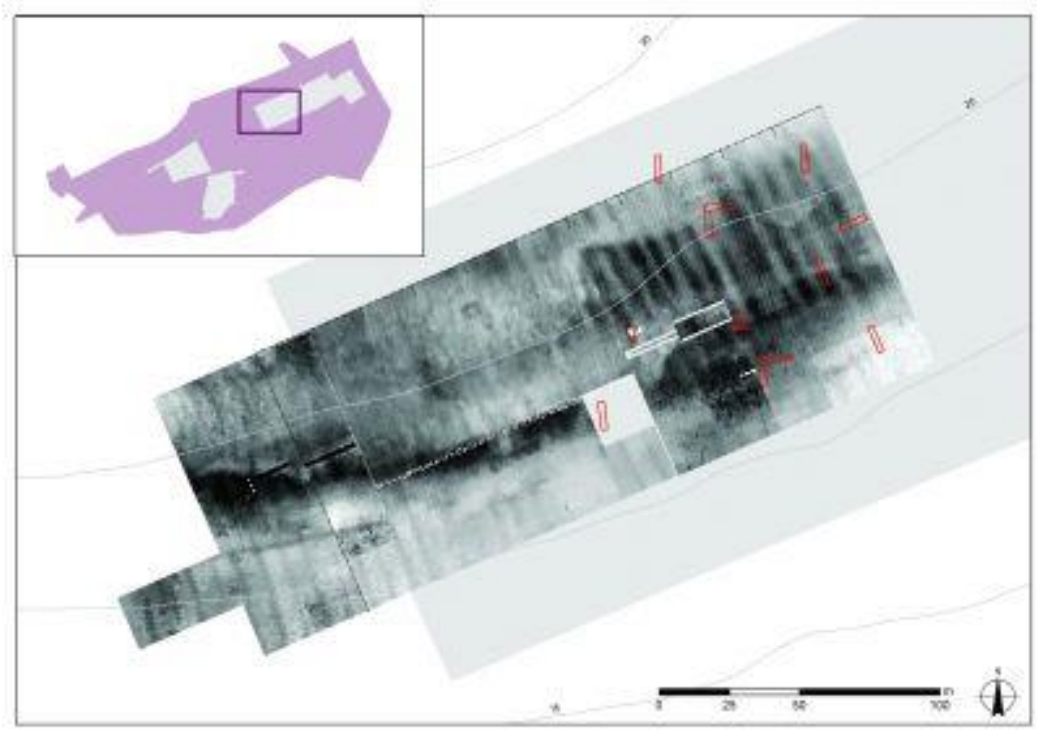

Figure 5: Patterning of geophysical prospection in one part of the site, darker areas indicating less damp zones. Trial trenches (red) were then set out in relation to this patterning, rather than distributed evenly across the development area

This iterative evaluation process, rarely possible in a purely commercial, time-limited context, generated a more accurate deposit model and the development of a research agenda with greater focus, allowing a more specific fieldwork strategy to emerge for Area A3. These more detailed procedures still had their limitations, however, notably in the modelling of preservation conditions on the site. Local variations in the latter (Figure 6) show that tactics needed to be adjusted, and research agendas remain fluid, in order to seize the unexpected opportunities offered by chance survival. More generally, only 
by understanding the diverse evaluation procedures embedded in archive documents is it possible to comprehend their implications for excavation strategy i.e. what was chosen for excavation, and what was ignored.

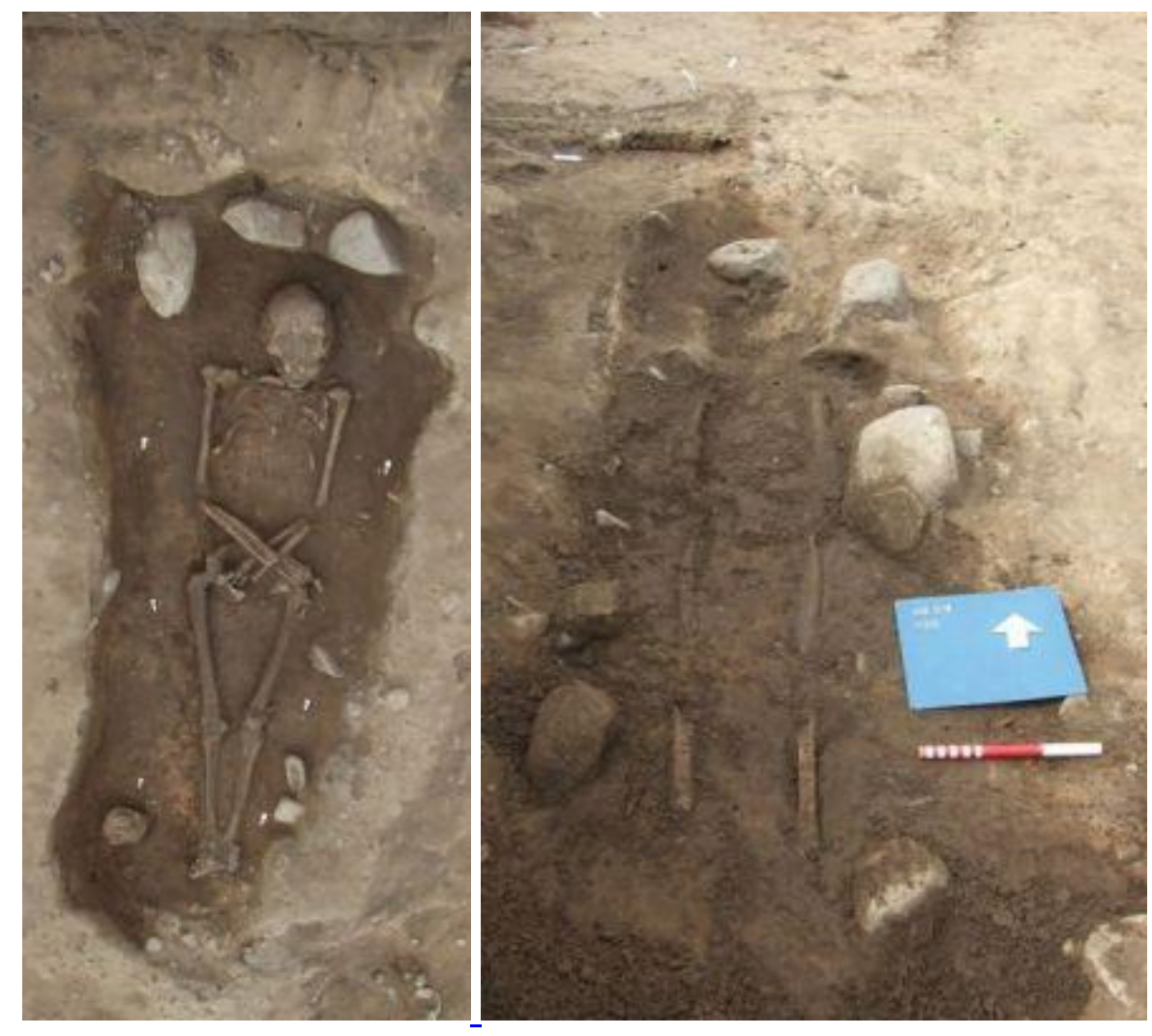

Figure 6a and 6b: Two adjacent Roman inhumations of similar date buried in the same subsoil, showing differential survival over small distances

Data gathering within excavated areas took a similar, fairly conventional, form in all three parts of the project: removal of topsoil, the majority by machine; definition and recording of the physical, spatial and stratigraphic characteristics of underlying features (mainly intrusions into subsoil, although horizontal strata were encountered fortuitously in one or two limited zones); and gathering of assemblages, either by hand or as environmental samples. Descriptive and stratigraphic records were generated and stored in analogous ways by each organisation.

There were, however, differences in detailed methodology, any of which might affect the interpretation of evidence. Thus topsoil was simply removed wholesale in the timelimited, commercial work of YAT and OSA, whereas the DoA operation endeavoured to gather finds from the topsoil via metal detecting and to plot their approximate distribution. Secondly, although each digital spatial record was recovered using similar instruments, it was obtained at different points in the excavation process: OSA took readings immediately after machining exposed new features, YAT and DoA following further cleaning and definition. The former approach has the advantage of not losing information if exposed areas dried out, but then had to be amended where it recorded 'features' later shown not to exist. The latter method produces an exact and internally consistent spatial record but runs the risk of being unable to re-locate intrusions visible on initial exposure. Finally, artefact recovery processes and environmental sampling 
strategies changed within organisations over time and diverged between them. As each was explicitly defined, however, they could be reconciled subsequently.

A final issue to raise here concerns a well-worn debate over the nature of the archaeological record derived from excavation (or indeed whether such exists:

Patrik 1985), something concealed within the above summary. The Heslington project drew upon systems designed during the 'Rescue years', which embody a division between recording and interpretation. This distinction has been criticised repeatedly in many quarters for creating an alienated environment in which recording is driven by dogma and fieldwork ossifies (successively, for example, Hodder 1997; Chadwick 2003; Carver 2011; and Watson 2019).

My response to this criticism is to define excavation as an interpretative engagement with the ground in an act of embodied practice (Roskams $\underline{2012}$. See also Carver 2006 and Edgeworth 2003; 2011). Thus diggers, when deploying physical labour in the material world, change both that world and themselves (in the process dissolving the subject/object dichotomy: Cobb et al. 2012). This act, then, is best viewed not as creating an objective record to preserve the past (Bonnie 2011), rather as a process of 'displacement' (Lucas $\underline{2001}, 38$ ). In this sense, excavated data could be seen as nondata: Buccellati 2017, 129.

Importantly, the digging activity of individual excavators may be 'rooted in established practice and an experienced knowledge base' (Buccellati 2017, 130), but such experiences are always generated in a collaborative context. Consultation when recording aspects of deposits such as their character, limits and stratigraphic relationships is commonplace, and indeed essential if the resulting records are to be linked together interpretatively afterwards. Changes in this collective context, I would argue, explain the present lack of on-site interpretation: it was not the advent of proforma recording in the 1970 s, a period during which interpretative engagement flourished (Thorpe 2012; Sandoval 2020), but the short-term nature of recent commercialised fieldwork that has degraded that 'experienced knowledge base' and thus generated a tendency to avoid interpretation.

This discussion of recording procedures has been examined in some detail because, as argued next, the proposed notion of displacement it is portrayed as embodying has much wider implications. Not only could both the process by which reconnaissance and evaluation evidence is used to define an excavation strategy and the act of excavation itself be described as forms of displacement, but so could various parts of later, postexcavation analyses. The creation of these archives, the main focus of the current article, is developed next.

\section{The General Character of Post- Excavation Analysis and Excavation Archives}

The notion of an 'archive objective' may have lain at the heart of the rationale for Rescue archaeology yet, in the profession's early days, policy formers discussing fieldwork tended to focus on the dissemination of its end product and how much detail this should 
contain (Department of Environment 1975; Council for British Archaeology/Department of Environment 1982; Carver et al. 1992), their objective being to define principles that prevented the discipline from 'drowning in data' (Thomas 1991). There was also debate over how physical archives might be stored and made accessible (issues still under discussion, albeit now transferred to a digital context: Everill and Irving 2015; Evans and Moore 2014). Little attention was devoted then, or has been since, to the form of such archives and, in particular, to the mechanisms for their production.

Thus, for example, the Department of Urban Archaeology, pivotal in the professionalisation of fieldwork in the City of London, did produce an Archive Report Writing Manual (Museum of London 1986) but this has proved far less influential than its system of proforma recording (Spence 1990). Later, Andrews et al. (2000) argued for using integrated databases to aid post-excavation analysis, but the latter are, essentially, convenient storage mechanisms, not analytical programmes per se. Carver (2009) is one of the few to provide more detail on this topic, discussing the role of assemblage, spatial and chronological analyses in the production of published syntheses.

My own approach leads me to see post-excavation programmes as requiring a rereading of the physical, spatial and stratigraphic record, best achieved by a sequence of (often iterative) decision making. These procedures comprise: combining lower-order, excavated stratigraphic units ('actions') to form higher-order categories ('activities'); grouping these into still higher-order entities on the basis of spatial and/or chronological characteristics ('phasing'); and feeding in assemblage analyses for function or dating to reach wider interpretations of feature types, periodisation etc.. Defining these entities into existence once fieldwork has finished represents, I suggest, another level of displacement beyond what has taken place in excavation (Lucas 2012, 169ff).

This line of reasoning has clear implications for the question of the role of on-site interpretation. Few would argue that all interpretation can be made when digging, and most would agree that any of that initial thinking would still need to be checked in the light of a more rounded understanding of the whole sequence, something by definition not available 'at the trowel's edge'. The above argument further implies that making secure decisions when converting actions into activities, defining phasing, and integrating assemblages with sequence would be all but impossible at the point of excavation.

Post-excavation analysis thus creates new categories of evidence, and any attempt to categorise the past is fraught with difficulty. Hamilton (1999) has noted that formal publications give little indication of the debates embodied in their writing. This is widely recognised in the definition of chronological groupings (see Introduction on transcending conventional periods in the Heslington monograph plus, for example, Roskams and Whyman 2007 on periodisation within Yorkshire's archaeology and Bradley 2007, 26, on such labels within prehistory). Yet corresponding questions arise equally when defining features and suggesting their functions, basic decisions needed to lay the foundations for any publication.

These complexities become clear immediately when one considers the chain of reasoning involved. Consider, for example, deciding that an excavated feature is a hearth on the basis of a concentration of charred material found on the surface of a stone slab. Is this material fairly undisturbed or has it just been dumped from elsewhere? If the former, is the underlying surface sufficiently charred to prove in situ burning? If 
exposed to considerable heat, does any surrounding stonework suggest actual construction, rather than opportunistic use of a convenient, pre-existing slab (the definition of a 'hearth' might arise at this point)? Further, if the adjacent stonework seems insufficiently convincing, could this still be a hearth but one whose superstructure has been subjected to later disturbance? And, if the latter is hypothesised, what sort of 'disturbance' is being proposed and is this suggestion consistent with other evidence for intrusive activity in the vicinity?

Furthermore, such basic decisions are needed even before one can distinguish between, for example, an iron-working hearth and a corn-drying oven on the basis of its residues: the decision to submit charred material for detailed analysis may itself depend on whether this feature is thought to be a hearth in the first place (prioritised if burning is in situ, not if redeposited). The same involved process of reasoning applies to every other interpretative category usually taken for granted - wall, pit, furrow, drainage channel etc.

Archives may provide important insights into pivotal points in the development of fieldwork practice, e.g. Bersu's excavations at Little Woodbury (Evans 1989) or Margaret Jones at Mucking (Evans et al. 2016, 1ff). Yet their fundamental role is to allow published interpretations to be interrogated by interested researchers, and doing so involves understanding how underlying evidence has been categorised. Admittedly, few readers will wish to take up this opportunity, at least immediately, but any failure to recognise this central role would be a death knell for the intellectual foundations of the discipline in the long term. The process of manipulating primary records to define higherorder entities needs to be exposed to scrutiny: we must 'show our working out'.

\section{Post-Excavation Assessment and Analysis at Heslington}

Post-excavation work at Heslington raised the above issues in concrete form. Some are related to the practical matter of bringing together work by different organisations, but others are rather more important, a product of conceptual problems embedded in any such analytical programmes. Initial spatial and stratigraphic analysis by YAT, OSA and DoA was followed by the assessment of assemblages generated in the field, as required by any MoRPHE-compliant project, leading to selective finds analysis. The results of all these work programmes then informed the publication strategy. The processes of analysing spatial, stratigraphic and assemblage classes of data are considered in turn next, followed by the challenges of integrating them into a coherent whole.

The problem of reconciling spatial data collected at different points in the fieldwork process has been noted previously. Once collated, all such information could be viewed conveniently in a single GIS database, even if this form of presentation still glosses over differences in defining the exact extent of layers and features during excavation. The stratigraphic component of this work was more difficult, however, due to the diverse formation processes involved and to assemblage sizes and context types being unevenly distributed through the sequence.

Critically, the process of grouping strata was approached quite differently by the three organisations involved, particularly in how, and at what stage, preliminary finds dating 
('spot dating') was incorporated into the work programme. Thus DoA records were placed in groups solely on the basis of site formation processes alongside stratigraphic and spatial criteria. A date was added to a group only at the end, based on either securely dated, associated material or the proposed date of any stratigraphically earlier group. YAT used a similar combination of deposit types, stratigraphy and spatial matters to define their groups, dating each by initial spot dates. OSA, in contrast, created groups on the basis of fuller pottery dating, alongside consideration of sequence and trench position.

Although superficially similar, the distinct approaches of each organisation express fundamentally different approaches to integrating finds dating and stratigraphy, from forming groups independent of recovered assemblages at one end of the spectrum to using detailed finds dating to create initial groups at the other.

Unsurprisingly, when combining these decisions to form a single sequence, as needed for the final synthesis, contradictions arose. This complex process of amalgamation can be understood only by 'drilling down' into the underlying stratigraphic reports.

A single example, excavated by YAT and allocated to group G153 in final analysis, illustrates some of the problems that arise. Ditch fill 1911 contained a deposit yielding a single coin of 3rd century CE date. Yet this feature was clearly cut by ditches G150 and G142 whose alignment and pottery contents date them securely to pre-Roman Iron Age, some centuries before the coin date. The stratigraphy is almost certainly correct: the Roman find is either intrusive or, much more likely, drifted into a hollow created above an underlying, long-disused pre-Roman feature. If one adds differential truncation by modern ploughing into this picture, then a single dated artefact from the uppermost fill of any large intrusion must be interpreted with considerable caution (see also discussion of the upper elements of a late Roman well on the site: Figure 11).

Having decided groupings on the basis of spatial and stratigraphic information, all excavated features were allocated a feature type. The aim here was to facilitate spatial analysis ('Where are the furrows on the site?') and to explore any relationships with assemblages ('Is a particular pottery type discarded differentially in boundary ditches?'). Some functional categories had been allocated provisionally by each of the three subprojects, but site-wide study required the definition of consistent, over-arching classes, based on a grasp of the whole sequence. In essence, the number of categories had to be simple enough to allow meaningful analysis, yet sufficiently numerous to fit the complexity of functions found here (not to mention grey areas and multiple feature use).

Naturally, the specific form of such thesauri, built bottom up, will vary between projects. Yet, as with the creation of stratigraphic groups, a simple functional label always conceals a multitude of intricate, and often questionable, arguments (see Section 5 on defining a 'hearth'). In the end, it was decided to focus only on primary function and, empirically, to divide excavated elements between: 'open cuts' (boundary, other linear ditch, curvilinear ditch, gully, furrow, land drain, and miscellaneous); 'closed cuts' (pit, posthole/stakehole, grave and miscellaneous); 'deposits' (ploughsoil, natural strata, spread, fill, skeleton, weathering); and 'structures' (kiln, hearth, structural slot, corn dryer, pad, wall, waterhole, cobbles, post-built structure and hypocaust). By connecting the spreadsheet listing these designated categories to the spatial database, it becomes easy to generate colour-coded plans of any zone (Figure 7). The apparent simplicity of this end product, however, hides the complex decision-making that preceded its production. 


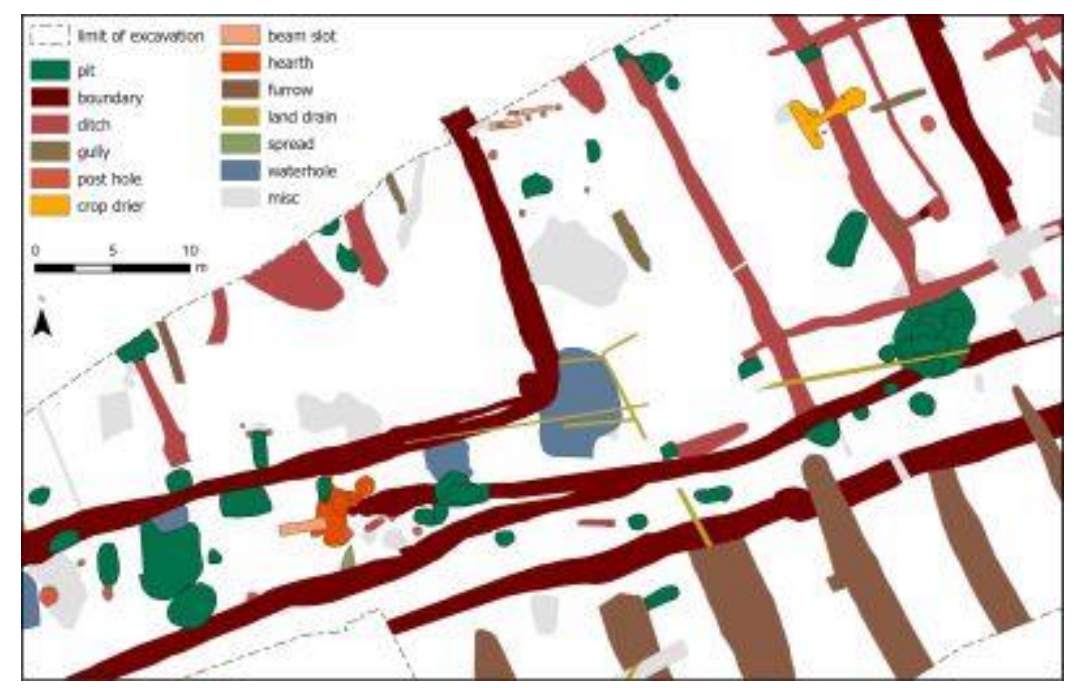

Figure 7: Colour-coded features plotted for one part of the Heslington site. Linear features distinguish between: major ditches (purple), subsidiary ditches (brown) and furrows (grey); and closed cuts between wells (blue), pits (lime green) and structural features (mid-green) (possible pits are in orange and a possible structural element in dark red, projections of linear features in violet)

These processes of reconciling the spatial record and forming overarching groups, then constructing feature types, ran alongside assemblage assessments to decide what subset of material types would be recommended for further analysis and at what level of detail. An added complexity at Heslington was that such strategic decisions were made about certain parts of the site a number of years before excavation was even started elsewhere. Possible inconsistencies were compounded by diverse approaches to the assessment process itself by different experts. Some assessors argued for a very selective approach when establishing priorities, hence focusing on well-preserved material deployed to answer a limited range of specific matters. Others, in contrast, put forward a wider-ranging programme that sought, essentially, to explore 'background noise' on the site.

In trying to confront such problems and reach meaningful conclusions, it became quickly apparent that the notion embedded in MoRPHE - of data collection, leading to assessment, leading to (selective) analysis - belied the iterative nature of postexcavation work. Thus, for example, items initially selected for conservation later yielded additional information requiring further specialist input. The need for the interpretative process to go back and forth between stratigraphic and assemblage analyses is an integral part of post-excavation work, but does not map easily onto the fragmented commercial context in which such work now takes place, with most finds specialists operating at arm's length. Furthermore, the latter outputs are usually paid for soon after being delivered in the first part of this loop. Hence any later work is then reliant on the goodwill of the people concerned having further, unpaid, conversations about collective understanding of the site (at Heslington, fortunately, these specialists always reengaged willingly with the project).

Beyond the above programmatic challenges, the notion of assessment to decide on more detailed examination involved deploying a variety of criteria. At Heslington, these included site context (formation processes and the primary or secondary status of deposits); date (material from unusual periods might be deemed more worthy than better-known counterparts - although, of course, the converse could also be argued); 
significance beyond Heslington (millstones, for example, constituted the largest collection yet from the region, so were examined in detail); the volume of material generated (certain questions can be answered only with large assemblages); and levels of survival (organic vs inorganic environmental samples).

In this list, recommendations on site context and date can be catered for using information from earlier parts of the post-excavation programme, while significance beyond Heslington rested on the expertise and background knowledge of the individual assessors. The relationship between assemblage size, quantification, and interpretative potential is more problematic, however, as is the question of using survival levels as a selection criterion. These two issues are explored more fully next.

Faunal assemblages provide a good example of the former difficulty. The project recovered 24,153 animal bone fragments. Most were hand-collected and such samples have their limitations analytically: large, visible bones, and thus certain animals and particular parts of animals, are over represented. Wet-sieving set volumes of soil would, no doubt, have generated a much more representative assemblage, but our resources did not allow this to be done on a sufficiently large scale. Where a small number of selected soil samples were sieved, these mostly yielded only tiny, often unidentifiable, bone fragments (such samples, unsurprisingly, did produce the only evidence for vole, shrew and fish). Just $14 \%$ of the total faunal assemblage was identifiable in detail and, while this still allowed some patterning to be recognised, only late Roman assemblages were large enough to generate meaningful metrical data (vital for studying animal stature and thus possible herd improvement over time). Furthermore, most bone groups were too small to give usable results on minimum number of individuals, the preferred measure when trying to explore the changing proportions of the main domesticates in a pastoral economy. Thus analysis had to employ fragment counts, and even here numbers could only be boosted to substantial levels by including unidentifiable elements in rough size categories (small allocated to sheep/goat, medium to pig, large to cattle or horse).

In interpreting this material, further matters had to be confronted. Although Heslington was a producing, not a consuming, site, the bones discarded here are unlikely to be an exact representation of what was raised in this landscape. In addition, most groups came from broad chronological categories (Table 1: the prehistoric category amalgamates all pre-Roman material, and the other columns are divided only by approximate Roman dates). Finally, and perhaps critically, each total amalgamates quite different feature types and must therefore embody diverse forms of deposition, plus degrees and types of redeposition of earlier material (see below on residuality). For the purposes of the published argument, however, it was felt that the patterning was so clear that this table made a valid statement, despite the huge range of complicating factors, difficult arguments and decisions that underpin its construction (the most contentious are made explicit in the published text, the more simple being incorporated into the archives). 
Table 1: Summary of faunal data for main domesticates by fragment count across main site periods

Prehistoric (\%) Early Roman (\%) Late Roman (\%)

$\begin{array}{lllll}\text { Cattle } & 20.80 & 88.10 & 78.30 & 83.80 \\ \text { Horse } & 8.30 & 0.90 & 3.90 & 3.60 \\ \text { Sheep/Goat } & 70.10 & 10.00 & 10.60 & 9.50 \\ \text { Pig } & 0.80 & 0.90 & 7.20 & 3.20\end{array}$

\section{Late Roman}

(\%)

The second pivotal issue concerns preservation. Defining excavation strategies on the basis of deposit models related to spacing, status and preservation (see Section 3 and Carver 2003) seems only reasonable, but the full impact of this decision making can only be appreciated fully in the course of assessing assemblages post-excavation. Carver's preservation criterion is, quite understandably, usually favoured in the field, notably by taking environmental samples where organic survival is maximised. The same strategic approach is then often applied when deciding which samples are most deserving of post-excavation resources. This combination of decisions at Heslington meant that we gained a detailed working knowledge of the woodland environment around each of its line of damp waterholes, but had only limited understanding of whether this was typical of the wider landscape beyond that springline. In addition, by concentrating on the preservation criterion more broadly, understanding of the pre-Bronze Age and medieval/modern parts of the sequence was de facto limited.

As set out above, preliminary thinking about formation processes, feature types and grouping influenced priorities in assemblage analysis. Yet the overall objective is not to simply juxtapose stratigraphy and assemblage but to fully integrate the results of the latter work into the former structures (Buccellati 2017, 102). Doing so led to a series of further issues. When linking assemblage studies to the spatial record, the significance of any distribution patterns can only be assessed if finds concentrations can be tested against soil volumes. Lacking the resources to calculate approximate volumes for every feature on the site in advance of detailed analysis, it was decided to do so only for that small sub-set of features where patterning of a specific artefact type seemed distinctive. In nearly all cases, the 'pattern' was then found to be a simple function of the amount of soil moved. The few exceptions include residues from prestigious metalworking discarded differentially in certain late Iron Age/early Roman roundhouses, and particular types of item signalling the closure of several wells or deposited in boundary ditch terminals.

Inevitably, the most difficult problems derived from the complex interaction between judgements based on interpretations of site formation processes, stratigraphic and spatial matters on the one hand, and finds dating on the other. Heslington sequences were dated by OSL, radiocarbon and, in one case, dendrochronological determinations, together with coins and pottery dates. Each such mechanism comes with its well-known potentials and limitations but, in our case, ceramic dating was critical and is used next to explore a range of topics. 
Pottery dates always incorporate different degrees of latitude between types, and may even be subject to more wholesale change when working in less well-researched spheres and/or with less diagnostic material. Heslington's pre- and post-Roman ceramics illustrate the problems here. Some of this material was 'claimed' by both Iron Age and Anglian specialists, and certain other sherds were not wanted by either (that late prehistoric and post-Roman ceramics are indistinguishable macroscopically is, of course, significant in its own right). The obvious solution to this conundrum, a programme of ceramic thin-sectioning, was beyond our means. The fact, however, that the distribution of proposed 'Anglian' ceramics matches that of other post-Roman artefacts suggests that some such identifications must be correct (Figure 8: the correspondence between the distribution of this material and that of very late Roman coins - both concentrated in a particular part of the site, even when deposit volumes have been taken into account - has important implications for the Roman/sub-Roman transition on the site).

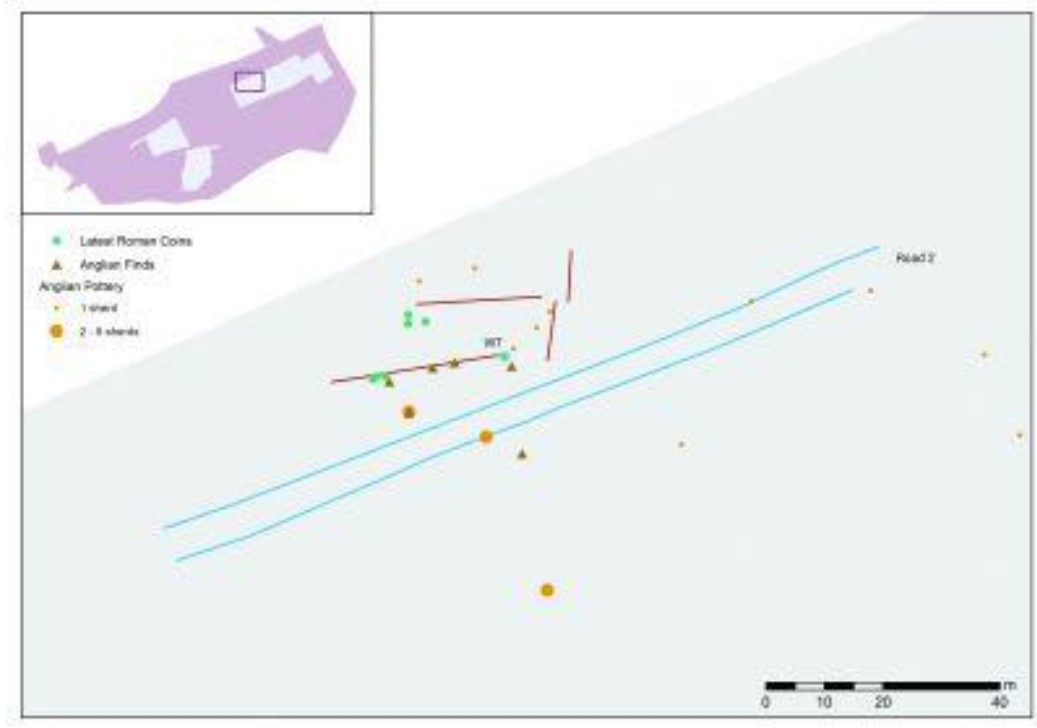

Figure 8: Features generating late 4th-century coins, probable Anglian finds and proposed Anglian ceramics. The linear features in red show the reorganisation of this landscape at the very end of the Roman period, or perhaps beyond

Although some inconsistency between stratigraphic and assemblage dates can be explained by the limitations of both sets of information, a more fundamental problem concerns the impact of intrusive and residual finds. Intrusion can usually be explained with a more careful consideration of context: did excavation of this stratigraphic unit occur in less than ideal conditions? Did the layer concerned lie immediately below modern topsoil? Is the uppermost deposit within a cut feature not really a 'fill' at all, rather much later soil, fortuitously surviving here but lacking elsewhere due to truncation (see above on a Late Roman coin in the top of an Iron Age ditch)? And so forth.

Sometimes, residuality can be equally obvious and explicable, for example with stonework re-used in a wellhead (Figure 9: whether this recycling has direct implications for structural development nearby or involved stonework being transported to the site from a distance remains unclear). 


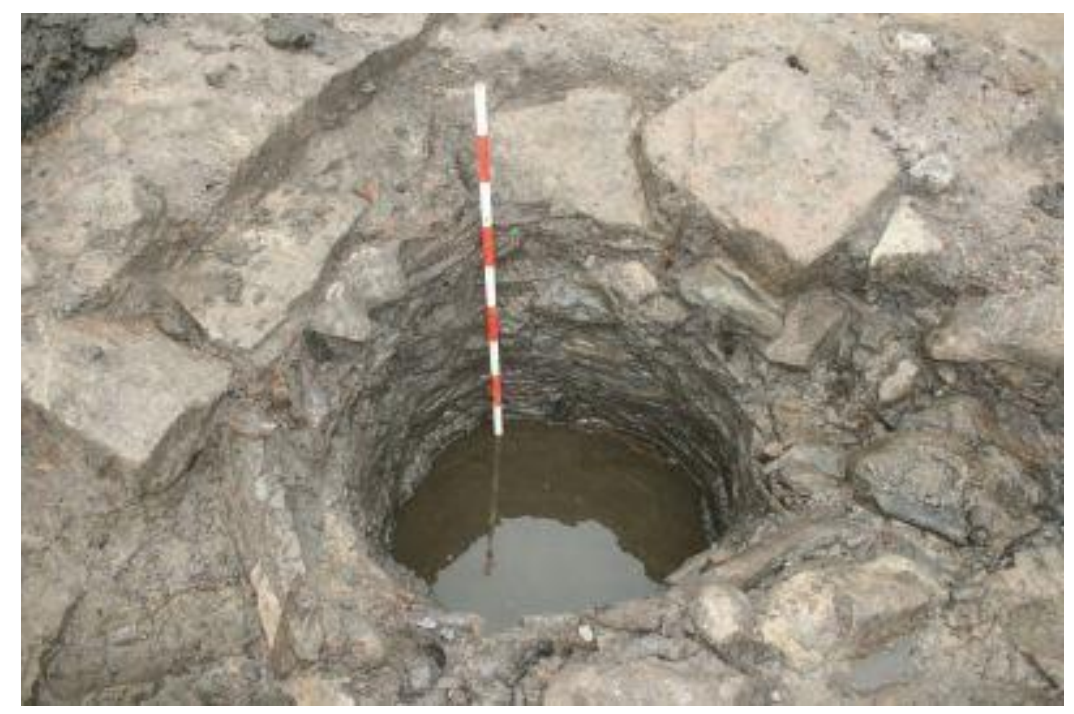

Figure 9: Well with wickerwork lining, capped with clearly re-used masonry @ Onsite Archaeology

More often, however, it can be much more challenging to identify residual finds. Horizontal stratigraphy may have formed over an extended period of time. Equally, ditches may have been dug and kept clean, then deliberately filled and re-cut, and finally levelled to prepare for future activity using material derived from a variety of sources. Indeed, the complex processes of gradual accumulation, re-cutting and dumping can be informative of social process in itself, for example in the filling of ditched enclosures between neighbouring households and collective ditch digging along trackways on the Yorkshire Wolds. Such work explains the tenacity of these communities, long-standing taskscapes binding them into the social fabric of the landscape (Giles 2007; Atha and Roskams 2012).

Notwithstanding the importance of understanding these depositional and cutting/recutting activities in their own right, the associated assemblages are often written off in assessment owing to residuality. This strategy would dismiss the vast majority of excavated material, which is usually residual to a greater or lesser extent. Such a selective approach may be a missed opportunity, however, for example by limiting the recognition of pottery sherd links, which have important implications for the movement of material around the site, and of ceramic redeposition through the sequence. The Heslington project took a more inclusive approach, with study of reworked material demonstrating, inter alia, that pottery from the very latest Roman levels was much less residual than the norm. This suggests reduced disturbance at the end of that period (the fact that this pattern matched numismatic profiles adds weight to it being a 'real' phenomenon).

Finally, if we had chosen to focus only on that small proportion of ceramics from primary contexts, it would have been impossible to define an overall ceramic signature for the site (Figure 10). The implication of the latter picture, that late Roman Heslington generally resembles other rural settlements in the vicinity but falls closer to forts, villas and urban sites in the early 4th century CE, has a validity independent of the diverse contexts from which this material was derived (see also Hurst and Roskams 1984 for a study of marble cladding from a site in Carthage whose very significance derives from the fact that this material cannot have come from any of the buildings there). 


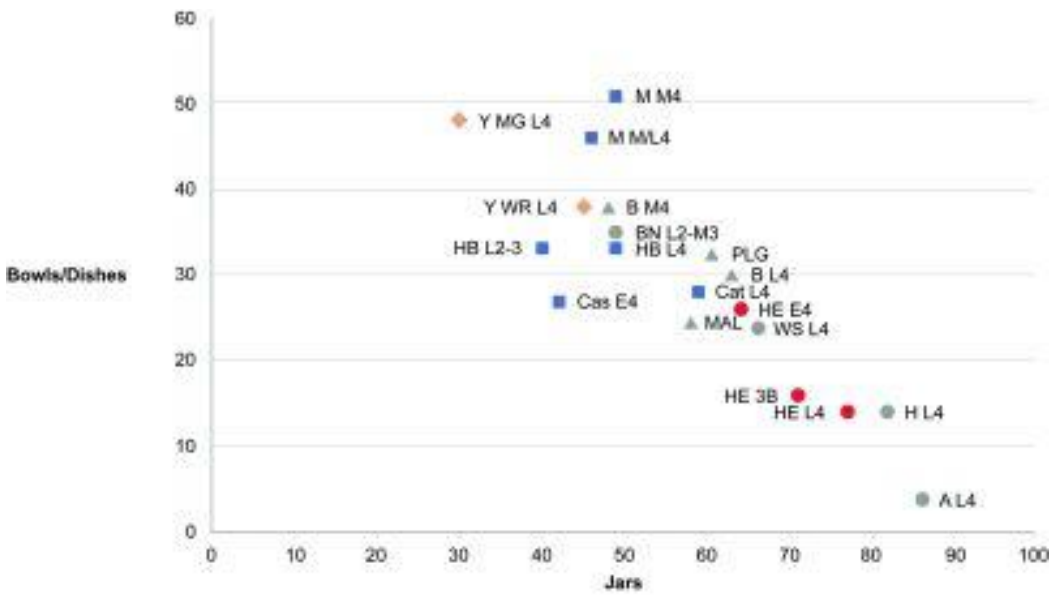

Figure 10: Roman period bowls/dishes (indicative of food serving) plotted against jars (storage), showing changes in Heslington signatures over time and compared with other sites in the Yorkshire region (York as diamonds, military sites squares, villas triangles, non-villa rural settlements circles). Heslington data is represented by red dots, divided between 3rd, early 4th and late 4th century CE materials. Assemblages from other centuries were too small to produce meaningful statistics

In the light of this long list of limitations and complexities, it is perhaps important to mention an example where the integration of different assemblage types with detailed stratigraphic information has managed to reach important conclusions about past human activity in this landscape, something published in advance of the monograph (Roskams et al. 2013). Where projects take decades to complete, the decision to disseminate a self-contained site feature before the main monograph is itself an additional sphere needing more discussion than it usually gets). This article concerned a deep, late Roman, masonry well, inserted in a seemingly anomalous position on the site and representing a major monumentalisation of part of the hillside. Using detailed stratigraphic, spatial, environmental, faunal, ceramic and stonework studies, it was possible to distinguish between primary silting (1), deliberate fouling of the water source (2), a closure deposit (3), episodic lining collapse interleaved with standing water (4) and post-Roman deposit accumulating long after it had fallen out of use (5) (Figure 11). This sequence of activities is interpreted as constituting a complex combination of ritual and routine practices. Any attempt to check those conclusions against the primary evidence would give some grasp of why clarification of archival structures is sorely needed. 


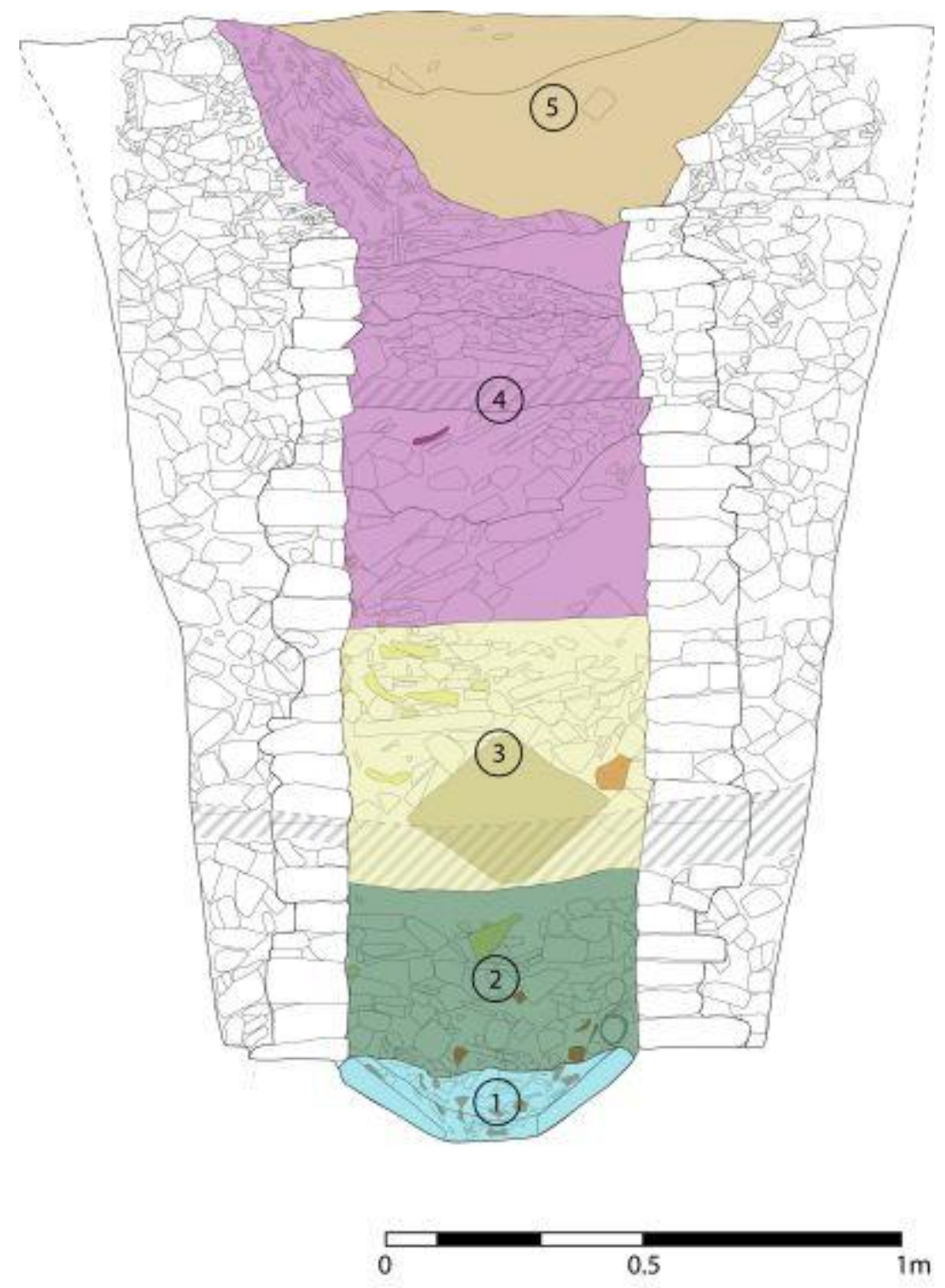

Figure 11: Profile of late Roman masonry well, indicating stages of backfilling

The final issue to explore concerning linking different forms of evidence derives from the decision to publish this project outside a conventional structure comprising: description of stratigraphic and structural development; summary of reports on assemblages; and concluding chronological discussion stretched over conventional divisions. As noted at the outset, we chose to not publish Heslington as a 'site' (itself clearly a problematic concept when modern development defines the limits of the work, and perhaps even with research projects: Buccellati 2017, 123ff) but to describe its development as a series of landscape engagements.

Although this brings advantages, it also has important implications for using the archive reports. Assemblages of human and animal bone, botanical materials and palaeoenvironmental studies already crossed period boundaries, so lent themselves to this approach. Indeed, the 'pivotal transitions' used to structure the concluding chapter of the monograph were informed, in part, by the invisibility of established periods in these reports, especially those reliant on radiocarbon dating (see also Bayliss $\underline{2015}$ and refs for a corresponding argument on how Bayesian modelling of radiocarbon dates might help to reconfigure prehistoric categories). In contrast, artefactual reports were less 
easily accommodated, most being produced by single-period specialists, most obviously prehistoric, Roman (itself with specialist subdivisions) and Anglian pottery.

The approach to both artefactual and ecofactual studies was to summarise each, in the process deciding what pieces of evidence were thought to be significant and thus worthy of publication (yet another level of displacement. Reading by other archaeologists would, hopefully, produce different emphases). The publication themes (natural resources, boundaries, food and other production, then domestic organisation, trade and exchange, and ritual activity: see Section 1) crosscut the content of each summary. So the latter were divided by colour codes mapped onto the chapter divisions.

Two of the largest assemblages, animal bone and pottery, show how this worked. Faunal studies informed, inter alia, the writing of methodology (ch. 1: bone quantification); food production (ch. 4: changing proportions of larger animals in the pastoral economy); consumption (ch. 7: burnt bone and butchery); and ideological practices (ch. 8: the structured deposition of animal parts in particular features or a suggested division between hunting dogs and lap dogs emerging in the Roman period). Equally, Roman ceramics were incorporated into the discussion of: methodology (ch. 1: fragmentation indices in relation to site formation processes); domestic structures (ch. 6: pottery lamps and lighting); consumption (ch. 7: vessels concerned with serving vs preparing food, and changes in local and long-distance pottery supply); and ideological practices (ch. 8: the deposition of particular pottery types in a boundary ditch, or a residual sherd of Ebor white ware made into a spindle whorl and placed as a grave good in the late Roman, crouched burial of a disabled male). It is only by using these colourcoded summaries in the archive that anyone but the most dedicated researcher could navigate from the published monograph down to the relevant section of a detailed specialist report.

\section{Conclusions}

As noted at the outset, the advent of PPG16 some 30 years ago signalled a move towards mitigation strategies, and much of our excavated evidence now comes out of the ground from small holes inserted in the process of site evaluation and written up in grey literature reports (Evans 2013). Thus these holes are dug to minimise the need for large-scale, destructive intervention, rather than to tell us about how any one part of the landscape was used in the past. I would argue that the discipline has some way to go in thinking through how data generated in this way can be used to reach useful conclusions about earlier social dynamics. Furthermore, the Heslington work shows that, even when extensive excavation is carried out, one can only publish meaningful interpretations by facing up to the difficult task of linking numerous, dispersed interventions and a great variety of specialist assemblage reports into a coherent whole.

Generating such interpretations in the course of post-excavation analysis is thus a complex process, and most readers of any synthetic publication will be prepared to take its conclusions at face value without feeling the need to delve further. Yet, hopefully, some at least may wish to explore underlying documentation, most likely when they disagree with the published reading of the evidence or cannot see how it has been derived from, or is justified by, what is presented there. In addition, future researchers may want to ask questions of a project that were not central to the interests of those who published the work, or indeed thought of as being significant (or even as being 'a 
question') when it was excavated. In these cases, the physical and digital archives will be a vital future resource.

The challenge of storing and accessing archaeological archives were first acknowledged in the Rescue Years (see Section 2) and digital mechanisms once seemed to be an important part of the solution. Thus it was claimed fairly recently that archival structures were now in place to allow 'comprehensive interpretation and reinterpretation of fieldwork results by any archaeologist who chooses to do so' (Aitchison 2010, 289: my emphases). Yet the nature of the archaeological archive remains acutely problematic, something acknowledged on both sides of the Atlantic (Kansa and Kansa 2018 for the US situation, below for UK literature), with many creators of commercial data following no formal selection and retention policies. Hence we are not just storing data but storing up problems.

By failing to consider methods of data production or to prioritise data by its re-use value, we risk losing much of importance in both our physical and digital archives. Today, many sections of society remain marginalised and excluded in their access to archaeological information and are thus dis-empowered (Evans and Wilson 2018; Bauer-Clapp and Kirakosian 2017). To rebalance these inequalities, we must ensure the application of all four of the FAIR principles which are meant to guide the management and stewardship of data. Clearly, it must be Findable, Accessible and Interoperable (Wright and Richards $\underline{2018}, 565)$ but, unless data is properly $\underline{\text { Re-usable, the first three principles }}$ become irrelevant.

Heslington's physical archive should be accessible in perpetuity at the Yorkshire Museum and its digital counterpart will be presented to the ADS for safeguarding (University of York, YAT, On-Site Archaeology 2013). The latter may allow access in the abstract, but will not, in itself, make this material a re-useable resource. As described previously, this documentation exists at a series of hierarchical levels, each influencing that after it in a process of translation and transition. Unless this sequence is made explicit, such an archive cannot play its assigned role(s). The five levels of interaction embodied in these outputs are described in Table 2.

Table 2: Summary of digital archive (in bold), held by ADS (University of York, YAT, On-Site Archaeology 2013), and physical archive $\left({ }^{*}\right)$, lodged at the Yorkshire Museum

Process

Reconnaissance and evaluation

Excavation

Initial postexcavation programme
Archive Content

Outcome

Outline deposit model

and research objectives defines priority areas and generates an excavation strategy fieldwalking, geophysical survey and trial
trenches/test pits Physical assemblages and hardcopy descriptive, stratigraphic and spatial data*

Reports on stratigraphic development, later consolidated into an overarching grouping system; single GIS linking all programme

Programme of selective specialist analyses
Initial post-excavation 


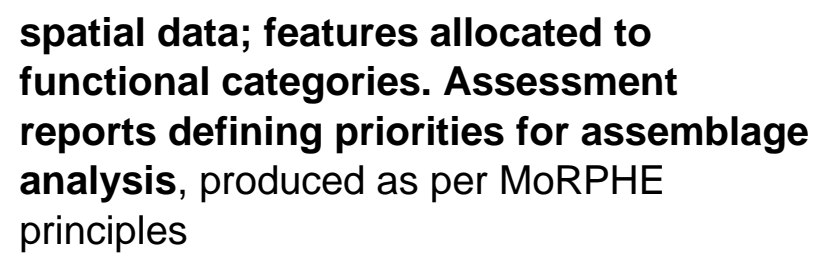

Secondary post-
excavation
programme

Publication programme
Reports on designated assemblages; commentaries integrating assemblages Publication with stratigraphic sequences, following programme iterative discussions

\section{Summaries of significant evidence, recast}

to fit the thematic organisation of the published report
Synthetic publication

First, the desk-based assessment and evaluation work of fieldwalking, geophysics and trial trenching carried out at the start of the project, once articulated in an outline deposit model, interacted with evolving research agendas to create the excavation strategy. This defined what areas were to be investigated and, more important, what were not and why, together with how this work would be carried out in terms of recording procedures and sampling strategies. The fact that, in our case, these decisions were taken by three organisations over several years, and with varied types of time pressure, added to the complexity of charting such interactions.

Second, implementation of that strategy in the field generated hardcopy descriptive, stratigraphic and spatial data and a range of physical assemblages and samples. This process of displacement in excavation is fundamental to the character of the archaeological record (Lucas 2001 and see section 4). The YAT component of this record was transferred to its IADB for long-term storage, manuscript information from the site being typed, not scanned, into that database. It is rarely recognised that the process of creating digital archives itself involves another sort of transformation (digital context sheets at Çatalhöyük, for example, merge field and laboratory data: Engel and Grossner 2015).

Third, preliminary examination of the resulting datasets represents another transition. Stratigraphic analysis took quite different forms in the three parts of the project, each organisation creating stand-alone interpretative phasing structures. These activities need to be understood in their own right, as does the difficult, and sometimes questionable, process required to then meld them into a coherent overall system of grouping. Spatial data from all three projects was consolidated into a single GIS, a process that flagged up inconsistencies in the latter record. Finally, the 'bottom up' definition of functional categories of feature and its application to all excavated contexts involved making grey areas appear black and white. All of these decisions then influenced how site assemblages were chosen for further analysis, as required by MoRPHE. The latter selection process not only rested on the contrasting stratigraphic foundations noted above, but also took place at different times and was carried out by specialists with diverse approaches to how to establish such priorities.

Fourth, the specialist reports commissioned at the previous stage had an iterative relationship with initial site analyses. Hence interpretations in either sphere might need amendment, or conflicts to be made explicit and proposed reconciliations explained. 
Owing to differential survival, divergent understandings of site formation processes, and variations in the incidence and form of redeposition of material on the site, these conversations were complex. They were made more so because most specialists worked at arm's length. In our case, fortunately, such discussions were possible because of the (largely unpaid) goodwill of the parties involved. This might suggest that commercialised fragmentation following neo-liberalisation of the fieldwork profession has yet to fully consume the staff working in it.

Fifth, distilling from those specialist outputs what two people thought was significant about Heslington, and then recasting these ideas into a series of landscape engagements, created a final level of translation. This involved reconfiguring summaries of specialist reports by colour-coding so that they could play different roles in that thematic structure.

The first of these transitions is common to most projects and, with some effort, can usually be understood using archived documentation, while the final one is a product of the specific decision to publish Heslington in a particular way. The three intervening processes, however, are common to most projects but are rarely discussed explicitly in the publications which they allow. Nor, in my experience, are they readily understandable using the archives deposited at the end of any project. This is a significant lacuna in our practice. Only by understanding these procedures and the resulting structures can we prevent poor published interpretations becoming fossilised or, much more common, ambiguities being crystallised into fact.

In any archaeological publication, it is rarely possible to set out definitive interpretations and, as stated at the outset, the Heslington monograph does not claim to be the 'final publication' of the site. Yet, if the discipline is serious in hoping for future engagement with its archives, it must pay attention to what is included in them and the complex hierarchical levels of decision-making that they embody. Further, this documentation needs to accommodate not only readers who arrive from the publication with questions to ask, but also much later audiences approaching from entirely different angles, for example with an interest in a particular find or feature type, or wanting to apply a newly developed analytical technique to a group of artefacts or ecofacts for which they require contextual information. It would be foolish to assume that any of these potential visitors can just be presented with a vast and complex archive and be expected to navigate their way through it. This project has tried to facilitate at least some of those yet to be defined journeys.

\section{Acknowledgements}

Many of the ideas set out above have been formulated in conversations over the years with numerous excavators on site and then with my co-director Cath Neal in the course of the Heslington project. All benefitted more recently from comments on draft text by my friends and colleagues Gustavo Sandoval, James Taylor and Holly Wright, together with those of two anonymous referees. Fault for the remaining incoherences must be laid at my door. 


\section{Bibliography}

Aitchison, K. 2010 'Grey literature, academic engagement, and preservation by understanding', Archaeologies: Journal of the World Archaeological Congress 6 (2), 289300. https:// doi.org/10.1007/s11759-010-9145-5

Andrews, G., Barrett, J.C. and Lewis, J. 2000 'Interpretation not record: the practice of archaeology', Antiquity 74(285), 525-30. https://doi.org/10.1017/S0003598X00059871

Atha, M. and Roskams, S. 2012 'Prehistoric and Roman transitions at Wharram Percy', in S. Wrathmell (ed) A History of Wharram Percy and Its Neighbours, York: University of York. 63-82.

Bauer-Clapp, H. and Kirakosian, K. 2017 'Archaeologists and archives: revisiting an old challenge', Advances in Archaeological Practice 5 (3), 220-

26. https://doi.org/10.1017/aap.2017.16

Bayliss, A. 2015 'Quality in Bayesian chronological models in archaeology', World Archaeology 47 (4), 677-700. https://doi.org/10.1080/00438243.2015.1067640

Bonnie, R. 2011 "'Haven't we dug enough now?" Excavation in the light of intergenerational equity', Archaeological Dialogues 18 (1), 48-

58. https://doi.org/10.1017/S1380203811000122

Bradley, R. 2007 The Prehistory of Britain and Ireland, Cambridge: Cambridge University Press. https://doi.org/10.1017/CBO9780511618574

Buccellati, G. 2017 A Critique of Archaeological Reason: structural, digital, and philosophical aspects of the excavated record, Cambridge: Cambridge University Press. https://doi.org/10.1017/9781107110298

Carver, M. 2003 Archaeological Value and Evaluation, Mantova: Societa Archeologica Padana.

Carver, M. 2006 'Thinking allowed', Rescue News 1009, 6-8.

Carver, M. 2009 Archaeological Investigation, London: Routledge.

Carver, M. 2011 Making Archaeology Happen: design vs. dogma, Walnut Creek, Calif: Left Coast Press.

Carver, M., Chapman, H., Cunliffe, B., Hassall, T., Hebditch, M., Lawson, A., Longworth, I., Morris, R., Phillipson, D., Schofield, J. and Wainwright, G. 1992 Archaeological Publication, Archives and Collections: Towards a National Policy, Society of Antiquaries and the Museums Association, London. (Printed as a supplement to British Archaeological News 7(2)). York.

Chadwick, A. 2003 'Post-processualism, professionalization and archaeological methodologies. Towards reflective and radical practice', Archaeological Dialogues 10 (1), 97-117. https://doi.org/10.1017/S1380203803001107 
Cherry, J., 2011. 'Still not digging, much', Archaeological Dialogues 18(1), 10 17. https://doi.org/10.1017/S1380203811000055

Cobb H., Harris, O.J.T., Jones, C. and Richardson, P. 2012 'Reconsidering archaeological fieldwork, an introduction: confronting tensions in fieldwork and theory' in H. Cobb, O.J.T. Harris, C. Jones and P. Richardson (eds) Reconsidering Archaeological Fieldwork: exploring on-site relationships between theory and practice, Boston, MA: Springer. 1-14. https://doi.org/10.1007/978-1-4614-2338-6 1

Cooney, G., 2009. 'European and global archaeologies', World Archaeology 41(4), 62628. https://doi.org/10.1080/00438240903402695

Council for British Archaeology/Department of Environment 1982 The Publication of Archaeological Excavations, Report of a Joint Working Party of the Council for British Archaeology and the Department of the Environment. London: Council for British Archaeology and Department of the Environment.

Darvill, T., Barrass, K., Constant, V., Milner, E. and Russell, B. 2019 Archaeology in the PPG16 Era: investigations in England, 1990-2010, Oxford: Oxbow Books.

Demoule, J-P. 2002 'Rescue archaeology: the French way', Public Archaeology 2(3), 170-77. https://doi.org/10.1179/pua.2002.2.3.170

Depaepe, P. 2016 'Preventive archaeology, scientific research and public outreach: some non-politically correct thoughts' in P. Novaković, M. Horňák, M. Guermandi, H. Stäuble, P. Depaepe and J-P. Demoule (eds) Recent Developments in Preventive Archaeology in Europe, Proceedings of the 22nd EAA Meeting in Vilnius, Ljubljana. 3340.

Department of Environment 1975 Principles of Publication in Rescue Archaeology, Report by a Working Party of the Ancient Monuments Board for England Committee for Rescue Archaeology. London: Department of the Environment.

Edgeworth, M. 2003 Acts of Discovery: An Ethnography of Archaeological Practice, British Archaeol. Rep. Int. Series 1131. Oxford: Archaeopress.

Edgeworth, M. 2011 'Excavation as a ground for archaeological knowledge', Archaeological Dialogues 18(1), 4446. https://doi.org/10.1017/S1380203811000109

Engel, C. and Grossner, K. 2015 'The archaeological process at Çatalhöyük: creating a living archive' in I. Hodder and A. Marciniak (eds) Themes in Contemporary Archaeology: Assembling Çatalhöyük, Leeds: Maney Publishing. 13-23.

Evans, C. 1989 'Archaeology and modern times: Bersu's Woodbury 1938 and 1939', Antiquity 63(240), 436-50. https://doi.org/10.1017/S0003598X00076419

Evans, C., Appleby, G. and Lucy, S. 2016 Lives in Land: Mucking excavations by Margaret and Tom Jones, 1965-78, Oxford: Oxbow Books. 
Evans, J. and Wilson, J., 2018. 'Inclusive archives and recordkeeping: towards a critical manifesto', International Journal of Heritage Studies 24(8), 857-

60. https://doi.org/10.1080/13527258.2018.1428671

Evans, T. 2013 'Holes in the archaeological record? A comparison of national event databases for the Historic Environment in England', The Historic Environment: Policy and Practice 4(1), 19-34. https://doi.org/10.1179/1756750513Z.00000000023

Evans, T.N.L. and Moore, R.H. 2014 'Beyond "The preserving machine": promoting use and reuse of grey literature and grey data', The Archaeological Review from Cambridge 29(2), 212-25.

Everill, P. and Irving, P. (eds) 2015 Rescue Archaeology. Foundations for the Future, Hertford: Rescue.

Giles, M. 2007 'Good fences make good neighbours? Exploring the ladder enclosures of late Iron Age East Yorkshire' in C. Haselgrove and T. Moore (eds), The Later Iron Age in Britain and Beyond. Oxford: Oxbow Books, 235-

49. https://doi.org/10.2307/i.ctvh1dsh9.15

Hamilton, S. 1999 'Lost in translation? A comment on the excavation report', Papers from the Institute of Archaeology 10, 1-8. https://doi.org/http://doi.org/10.5334/pia.140

Historic England 2006 Management of Research Projects in the Historic Environment: The MoRPHE Project Managers' Guide. London: Historic England.

Hodder, I. 1997 "'Always momentary, fluid and flexible": towards a reflexive excavation methodology', Antiquity 71(273), 691-700. https://doi.org/10.1017/S0003598X00085410

Hurst, H. and Roskams, S. 1984 Excavations at Carthage: the British Mission, vol. 1.1: The Avenue de President Habib Bourguiba, Salammbo: The Site and Finds other than Pottery. Sheffield: British Academy.

Jackson, S., Lennox, R., Neal, C., Roskams, S., Hearle, J. and Brown, L. 2014 'Engaging communities in the 'Big Society': What impact is the localism agenda having on community archaeology?', The Historic Environment: Policy and Practice 5(1), 7488. https://doi.org/10.1179/1756750513Z.00000000043

Kansa, S. and Kansa, E. 2018 'Data beyond the archive in digital archaeology: an introduction to the special section', Advances in Archaeological Practice 6(2), 8992. https://doi.org/10.1017/aap.2018.7

Landward Research Ltd 2014 Profiling the Profession. York: Archaeology Data Service. https://doi.org/10.5284/1024571

Lucas, G. 2001 'Destruction and the rhetoric of excavation', Norwegian Archaeological Review 31, 35-46. https://doi.org/10.1080/00293650119347

Lucas G. 2012 Critical Approaches to Fieldwork: Contemporary and Historical Archaeological Practice. London: Routledge. 
Museum of London 1986 DUA Archive Report Writing Manual. Unpublished: Museum of London.

Neal, C. and Roskams, S. 2013 'Authority and Community: reflections on archaeological practice at Heslington East, York', Historic Environment: Policy and Practice 4(2), 139 55. https://doi.org/10.1179/1756750513Z.00000000032

Novakoviç, P., Horňák, M., Guermandi, M., Stäuble, H., Depaepe, P. and Demoule, J-P. (eds) 2016 Recent Developments in Preventive Archaeology in Europe, Proceedings of the 22nd EAA Meeting in Vilnius, Ljubljana.

Orange, H. and Perring, D. 2017 'Commercial archaeology in the UK: public interest, benefit and engagement' in G. Moshenka (ed) Key Concepts in Public Archaeology, London: UCL Press. 139-50. https://doi.org/10.2307/j.ctt1vxm8r7.14

Patrik, L. 1985 'Is there an archaeological record?', Advances in Archaeological Method and Theory 8, 27-62. https://doi.org/10.1016/B978-0-12-003108-5.50007-5

Perring, D. 1999 Heslington Campus, City of York, Unpublished report: University of York.

Planning Policy Guidance (PPG) 161990 Archaeology and planning https://webarchive.nationalarchives.gov.uk/20100305092137/http://www.comm unities.gov.uk/documents/planningandbuilding/pdf/156777.pdf

Rahtz, P. (ed) 1974 Rescue Archaeology, Harmondsworth: Penguin.

Ronayne, M. 2008 'The state we're in on the eve of World Archaeological Congress (WAC) 6: Archaeology in Ireland vs Corporate Takeover and a Reply from University College Dublin', Public Archaeology 7(2), 114-

31, https://doi.org/10.1179/175355308X330016

Roskams, S. 2001 Excavation, Cambridge: Cambridge University Press.

Roskams, S. 2012 'Late Antique field archaeology: a legitimate aim?' in L. Lavan and M. Mulryan (eds) Field Methods and Post-Excavation Techniques in Late Antique Archaeology, Leiden: Brill. 17-50.

Roskams, S. and Neal, C. 2020 Landscape and Settlement in the Vale of York: Archaeological investigations at Heslington East, York, 2003-13, London: Society of Antiquaries of London. https://doi.org/10.26530/20.500.12657/39942

Roskams, S. and Whyman, M. 2007 'Categorising the past: lessons from the archaeological resource assessment for Yorkshire', Internet

Archaeology 23. https://doi.org/10.11141/ia.23.2

Roskams, S., Neal, C., Richardson, J., and Leary, R. 2013 'A Late Roman well at Heslington East, York: ritual or routine practices?', Internet

Archaeology 34. https://doi.org/10.11141/ia.34.5 
Sandoval, G. 2020 An Epistomology of Archaeological Excavation: a comparative study of British field practice, Unpublished PhD: University of York.

Schlanger, N. and Aitchison, K. (eds) 2010 Archaeology and the Global Economic Crisis: multiple impacts, possible solutions, Tervuren, Belgium: Culture Lab Editions.

Spence, C. 1990 The Museum of London Archaeological Site Manual, 2nd edition. London: Museum of London Archaeology Service.

Stefánsdóttir, A. 2019 'An introduction to development-led archaeology in Europe: meeting the needs of archaeologists, developers and the public', Internet Archaeology 51. https://doi.org/10.11141/ia.51.9

Thomas, R.M. 1991 'Drowning in data? Publication and rescue archaeology in the 1990s', Antiquity 65(4), 822-28. https://doi.org/10.1017/S0003598X00080546

Thorpe, R. 2012 'Often fun, usually messy: fieldwork, recording and higher orders of things' in H. Cobb, O.J.T Harris, C. Jones and P. Richardson (eds) Reconsidering Archaeological Fieldwork: exploring on-site relationships between theory and practice, Boston, MA: Springer, 31-52. https://doi.org/10.1007/978-1-4614-2338-6 3

Watson, S. 2019 'Whither archaeologists? Continuing challenges to field practice'. Antiquity 93(372), 1643-52. https://doi.org/10.15184/aqy.2019.141

University of York, York Archaeological Trust, On-Site Archaeology 2013 Heslington East Excavation Archive [data-set]. York: Archaeology Data Service [distributor] https://doi.org/10.5284/1019860

Webley, L., Vander Linden, M., Haselgrove, C. and Bradley, R. (eds) 2012 Development-led Archaeology in Northwest Europe: proceedings of a round table at the University of Leicester, 19th-21st November 2009, Oxford: Oxbow Books. https://doi.org/10.2307/j.ctvh1dvc8

Wright, H. and Richards, J. 2018 'Reflections on collaborative archaeology and largescale online research infrastructures', Journal of Field Archaeology 43, sup. 1, S60S67. https://doi.org/10.1080/00934690.2018.1511960 